\title{
A scientific note on first detection of Kashmir bee virus in Apis mellifera (Hymenoptera: Apidae) in South America
}

\author{
Gustavo Riveros $^{1}$, Nolberto Arismendi ${ }^{1}$, Nelson Zapata $^{2}$, Guy Smagghe ${ }^{3}$, Marta Rodríguez ${ }^{4}$, Marcos Gerding ${ }^{4}$, \\ Marisol VARGAS ${ }^{1}$ \\ ${ }^{1}$ Laboratories of Virology and Bee Pathology, Faculty of Agronomy, Universidad de Concepción, Av. Vicente Méndez 595 , \\ Chillán, Chile \\ ${ }^{2}$ Departament of Plant Production, Faculty of Agronomy, Universidad de Concepción, Av. Vicente Méndez 595, Chillán, Chile \\ ${ }^{3}$ Faculty of Bioscience Engineering, University of Ghent, Coupure Link 653, 9000, Ghent, Belgium \\ ${ }^{4}$ Centro de Producción de Insectos Benéficos BioBichos Ltda, Variante Cato s/n, Chillán, Chile
}

Received 26 February 2017 - Revised 18 August 2017 - Accepted 1 September 2017

KBV / honey bee / real-time PCR / virus prevalence

The honey bee (Apis mellifera L.) is considered an important pollinator for many agricultural crops and other non-domesticated plant species worldwide (Potts et al. 2010). Similar to other agricultural-based countries, beekeeping is an important activity in Chile, not only because it provides pollination services for fruit and seed production, but also because it exports honey bee products to other countries. Although there is not enough published information about the mortality of colonies in Chile, beekeepers have undergone an increasing loss of colonies in recent years. Possible causes for these losses are still unclear, but these mortalities coincide with recent honey bee colony losses around the world (Neumann and Carreck 2010).

Several pathogens, including honey bee viruses, have been involved in honey bee colony collapse disorder (Cox-Foster et al. 2007). Currently, about 24 viruses have been identified in honey bees worldwide. Although some of these viruses produce recognizable symptoms at sufficiently elevated titers, generally, they naturally persist in honey bee populations at low levels (de Miranda et al. 2013). Several viruses are closely

Electronic supplementary material The online version of this article (https://doi.org/10.1007/s13592-017-0545-z) contains supplementary material, which is available to authorized users.

Corresponding author: M. Vargas, marisolvargas@udec.cl

Manuscript editor: Stan Schneider enough related to be regarded as members of a single species complex; these complexes are acute bee paralysis virus (ABPV), Kashmir bee virus (KBV), and Israeli acute paralysis virus (IAPV), all of which are non-enveloped and positive-stranded RNA viruses that belong to the Dicistroviridae family (King et al. 2011). KBV is a potentially lethal virus within honey bee hives. It is thought to persist as an unapparent infection within the bee community, producing vague, non-descript symptoms, until stress or Varroa destructor Anderson and Trueman infestation causes it to become epidemic and fatal (de Miranda et al. 2013). KBV has been detected in several countries around the world (Ellis and Munn 2005). However, no previous studies have reported KBV presence in South American countries (Maggi et al. 2016).

A group of 50 worker bees were collected between the spring of 2014 and the fall of 2015 from 467 bee hives located in the Metropolitan (RM, 33 $26^{\prime} \mathrm{S}-70^{\circ}$ $39^{\prime} \mathrm{W}$ ), O'Higgins (VI, $34^{\circ} 10^{\prime} \mathrm{S}-70^{\circ} 43^{\prime} \mathrm{W}$ ), Maule (VII, $35^{\circ} 25^{\prime} \mathrm{S}-71^{\circ} 39^{\prime} \mathrm{W}$ ), Bio-Bío (VIII, $36^{\circ} 46^{\prime} \mathrm{S}-$ $73^{\circ} 03^{\prime} \mathrm{W}$ ), and Araucanía (IX, $38^{\circ} 44^{\prime} \mathrm{S}-72^{\circ} 35^{\prime} \mathrm{W}$ ) regions of Chile. Ten honey bees were crushed and homogenized according to Arismendi et al. (2016) and supernatant was used for RNA isolation, according to Rodríguez et al. (2014). The first-strand cDNA synthesis was performed using the M-MLV reverse transcriptase enzyme (Invitrogen, Life Technologies, Carlsbad, $\mathrm{CA}$ ) according to the manufacturer's recommendations.

Conventional PCRs were run using universal primers for the ABPV-KBV-IAPV complex; these consisted of 
AIKVf 5'-GGTGCCCTATTTAGGGTGAGGA-3' (Reynaldi et al. 2013) and AKIr 5'-AAAC TGAATAATACTGTGCGTA-3' (Francis and Kryger 2012), which amplified a fraction of the intergenic and structural polyprotein regions of the viruses. The amplified DNA fragments $(320 \mathrm{pb})$ were purified and directly sequenced in both directions (Macrogen, Seoul, South Korea). Analyses of the similarities among sequences were carried out with the Basic Local Alignment Search Tool (BLAST, NCBI) and then compared online for homologies (T-coffee) with other sequences in the European Bioinformatics Institute database (EBI, Cambridge, UK). To determine the phylogenetic relationships with other honey bee viruses, a phylogenetic tree was constructed with Seaview 4.0 using the neighbor-joining method with 1000 bootstraps for ABPV, IAPV, and KBV reported in different countries (Figure 1). Solenopsis invicta virus 1 was used as the root of the tree in the phylogenetic analysis.
In order to detect the prevalence of KBV in Chilean honey bee apiaries, a specific real-time PCR (Stratagene Mx3000P, Agilent Technologies, CA) was conducted. The PCR reactions were carried out in $15 \mu \mathrm{L}$ containing $1 X$ of KAPA SYBR FAST Universal 2X qPCR Master Mix (Kapa Biosystems, Wilmington, MA, USA) and $530 \mathrm{nM}$ of each primer (KBV-F and KBV-R, Supplementary Material). Primers $\beta$-actin-F and $\beta$-actin-R, which amplify the honey bee's actin gene, were used as an internal control (Supplementary Material).

The combination of the primers AIKVf (Reynaldi et al. 2013) and AKIr (Francis and Kryger 2012) was able to amplify around $320 \mathrm{pb}$ (data not shown). The sequenced fragments were identified as KBV and the multiple sequence alignment with other KBV sequences, as well as with ABPV and IAPV sequences deposited in GenBank, allowed us to detect a gap in $\mathrm{KBV}$ and in ABPV of three and six nucleotides compared with IAPV, respectively (Figure 1a). KBV and

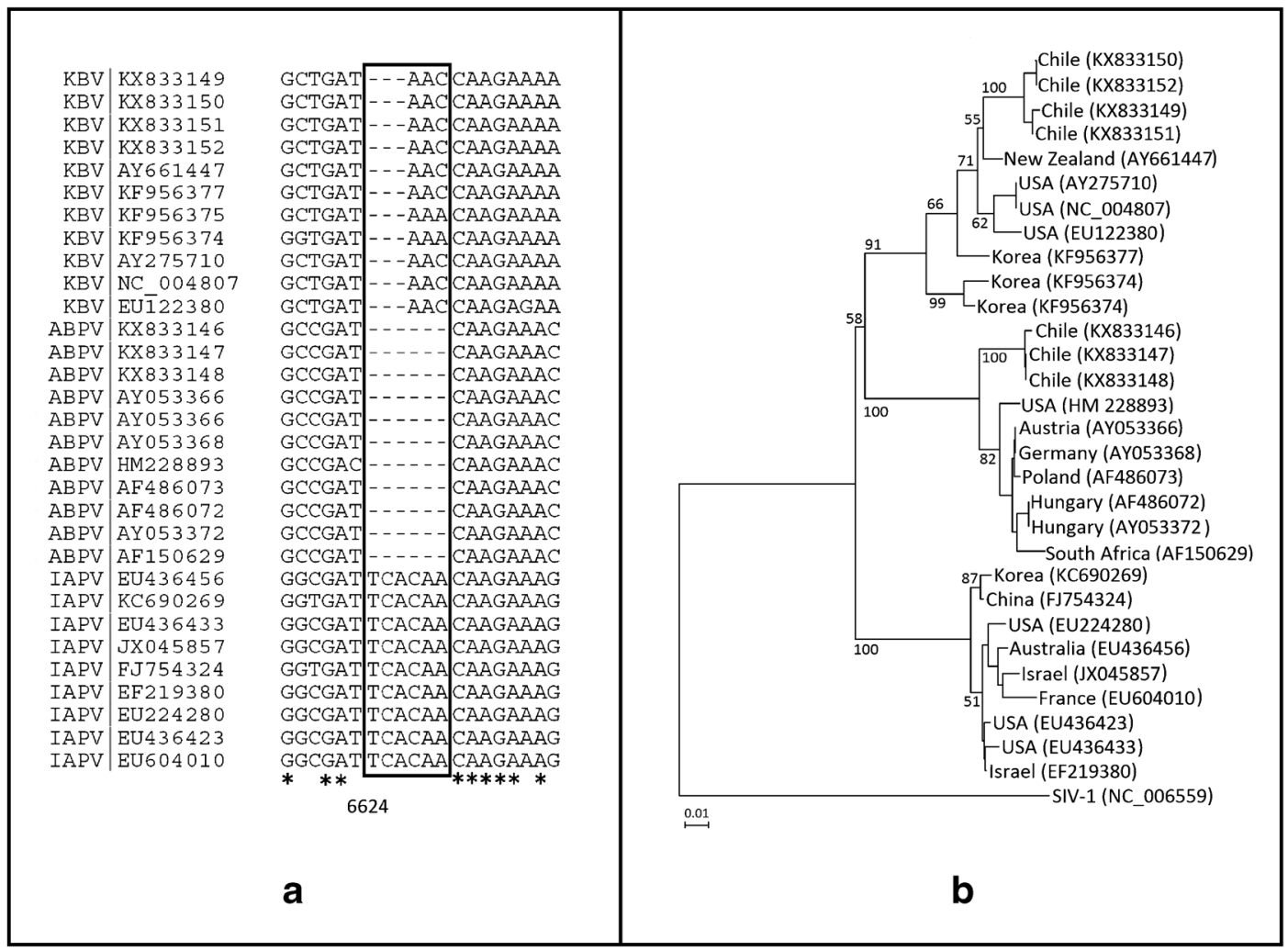

Fig. 1. a Sequence alignments of KBV, IAPV, and ABPV. The black square shows the nucleotide position with respect to the IAPV genome (EF219380). b Phylogenetic tree constructed by the neighbor-joining method using a fraction of the intergenic and structural polyprotein regions of KBV from Chile. KBV, IAPV, and ABPV sequences published in the GenBank were also included in the analysis. Solenopsis invicta virus 1 was used as out-group and numbers from each branch indicate bootstrap values ( $>50 \%$ support values are shown with 1000 replicates). 
ABPV sequences showed a consistent gap from nucleotide 6624 to 6626 and 6624 to 6629 when these sequences were aligned with the IAPV genome (EF219380), respectively (Figure 1a). This combination of primers allows by one single PCR reaction and confirms by sequencing to detect and identify the KBV infection for the first time in Chilean apiaries. The aforementioned primers amplified a short but informative part of the genome of the ABPV-IAPV-KBV complex, allowing us to discriminate KBV from ABPV and IAPV. In some cases, it is difficult to discriminate one virus from another because they are so closely related (de Miranda et al. 2010). The phylogenetic tree constructed with sequences obtained with the AIKVf/ AKIr primers showed that Chilean KBV shares the same clade with a high bootstrap value $(100 \%)$ more related with KBV reported in New Zealand than that detected in USA and Korea (Figure 1b).

Real-time PCR using specific primers (KBV-F and KBV-R, Supplementary Material) allowed us to detect KBV from honey bee samples in Chilean apiaries. Honey bees collected from hives in the Maule region were the most infected (32.1\%), followed by O'Higgins $(15.4 \%)$, the Metropolitana (12.5\%), Bio-Bio (9.2\%), and Araucanía regions (5.4\%). These data demonstrate that $\mathrm{KBV}$ is widely dispersed in Chile and the distribution of this virus throughout the country could be associated with transhumance, or the buying and selling of queens and honey bee nucleuses throughout all regions of the country. Furthermore, $V$. destructor, which is widely distributed throughout Chile, acts as a vector of $\mathrm{KBV}$ and other viruses in honey bee colonies (de Miranda et al. 2013). There exists the possibility that the management of $V$. destructor affects KBV prevalence in some regions. However, the control of this parasite in these apicultural regions is well known and standardized; therefore, we have no evidence that management of $V$. destructor may influence in KBV prevalence and distribution in Chile. New researches are required.

This is the first report of honey bees infected with $\mathrm{KBV}$ in Chile. The origin of this pathogen in the country is still unclear. KBV could have been introduced into Chile by the importation of queen bees from Europe. The dominant honey bee subspecies in Chile are Apis mellifera ligustica Spinola and Apis m. carnica Pollman which have been imported from Italy and Austria, respectively (Fuller and García 2006). There is evidence that KBV has been detected in these countries as well, especially in Italy (Cersini et al. 2013). However, we have no evidence that queens originating from these countries have $\mathrm{KBV}$ or other honey bee viruses previously reported in Chile (Rodríguez et al., 2014).
This is also considered the first report of KBV in South America. Previous studies in South America have not yet reported the presence of this important pathogen (Maggi et al. 2016). In neighboring countries, KBVrelated viruses, such as IAPV, which was highly prevalent (Reynaldi et al. 2011), have also been reported. However, primers used in that study for viral detection in honey bee samples are not only able to detect IAPV, but also can amplify KBV and thus could overestimate the prevalence of IAPV.

Honey bees infected with KBV have no reported visible symptoms and experimental evidence in longterm studies has shown that KBV can be extremely lethal to honey bee larvae and adults (de Miranda et al. 2013). Thus, the presence of viruses and other pathogens could explain the winter bee mortality in Chile; therefore, it is important to study the epidemiology and the impact that viral diseases could have in Chilean apiaries in order to understand the best way to manage and control them.

\section{ACKNOWLEDGMENTS}

This study was supported by Grants FONDECYT $\mathrm{N}^{\circ} 1140653$ from the National Commission for Scientific and Technological Research, CONICYT, Chile.

\section{CONTRIBUTIONS}

MV conceived this research; GR, performed experiments and analysis; GR, NA, NZ, and GS participated in the design and interpretation of the data; MR and MG participated in collection of bee samples. All authors read and approved the final manuscript.

Note scientifique sur la première détection du virus du Cachemire chez Apis mellifera (Hymenoptera: Apidae) en Amérique du Sud

Eine wissenschaftliche Notiz zum ersten Nachweis des Kaschmir-Bienen-Virus bei Apis mellifera (Hymenoptera: Apidae) in Südamerika

\section{REFERENCES}

Arismendi, N., Bruna A., Zapata N., Vargas M. (2016) PCRspecific detection of recently described Lotmaria passim (Trypanosomatidae) in Chilean apiaries. J. Invertebr. Pathol. $134: 1-5$. 
Cersini A., Bellucci V., Lucci S, Mutinelli F., et al. (2013) First isolation of Kashmir bee virus (KBV) in Italy. J. Apic. Res. $52: 54-55$.

Cox-Foster DL, Conlan S., Holmes EC, Palacios G, Evans JD, et al. (2007) A metagenomic survey of microbes in honey bee colony collapse disorder. Science $318: 283-287$.

de Miranda JR, Cordoni G, Budge G. (2010) The acute bee paralysis virus - Kashmir bee virus - Israeli acute paralysis virus complex. J. Invertebr. Pathol. $103: 30-47$.

de Miranda JR, Baley L, Ball BV, Blanchard P., et al (2013) Standard methods for virus research in Apis mellifera. J. Apic. Res. $52: 1-55$.

Ellis J.D., Munn P.A. (2005) The worldwide health status of honey bees. Bee World $86: 88-101$.

Francis R., Kryger P. (2012) Single assay detection of acute bee paralysis virus, Kashmir bee virus and Israeli acute paralysis virus. J. Apic. Sci. $56: 137-146$.

Fuller J., García P. (2006) Cuarentena en confinamiento de abejas reinas, V Región 2005. Boletín Veterinario Oficial Nº7 1-14.

King AM, Adams, MJ, Carstens EB, Lefkowitz E.J. (2011) Virus taxonomy: ninth report of the International Committee on
Taxonomy of Viruses. Elsevier Academic Press, San Diego.

Maggi M, Antúnez K, Invernizzi C, Aldea P., et al. (2016) Honeybee health in South America. Apidologie 47 :835-854.

Neumann P, Carreck NL (2010) Honey bee colony losses. J. Apic. Res. 49:1-6.

Potts SG, Biesmeijer JC, Kremen C, Neumann P., et al. (2010) Global pollinator declines: trends, impacts and drivers. Trends Ecol. Evol. 25 :345-353.

Reynaldi, F. J., Sguazza, G. H., Tizzano, M. A., Fuentealba, N., et al. (2011). First report of Israeli acute paralysis virus in asymptomatic hives of Argentina. Rev. Argent. Microbiol., 43 (2): 84-86.

Reynaldi FJ, Sguazza GH, Albicoro FJ, Pecoraro MR., et al. (2013) First molecular detection of co-infection of honey bee viruses in asymptomatic Bombus atratus in South America. Braz. J. Biol. $73: 797-800$.

Rodríguez M, Vargas M, Antúnez K, Gerding M., et al. (2014) Prevalence and phylogenetic analysis of honey bee viruses in the Biobío Region of Chile and their association with other honey bee pathogens. Chilean J. Agric. Res. $74: 170-177$. 